\title{
MOLECULAR GENETICS OF \\ AUTOSOMAL RECESSIVE SPINAL MUSCULAR ATROPHY
}

\author{
Nanda R. Rodrigues, Kevin Talbot, and Kay E. Davies \\ Genetics Laboratory, Biochemistry Department, University of Oxford, \\ Oxford, United Kingdom
}

Childhood-onset proximal spinal muscular atrophy (SMA) is characterized by degeneration of the anterior horn cells of the spinal cord leading to symmetrical limb and trunk paralysis. SMA is the second most common fatal autosomal recessive disease of early life after cystic fibrosis, with an incidence of between 1 in 6,000 to 1 in 10,000 live births (1). Subdivision is based on the age of onset of symptoms, which tends to reflect disease severity. Type I, Werdnig-Hoffman disease, is lethal in infants and manifests at birth or within 6 months of age. These patients never sit unaided. Type II patients sit, but never walk unaided, and survival depends on how much the respiratory muscles are affected. Type III SMA (KugelbergWelander disease) is a relatively mild disorder with onset in adolescence or later (2). In contrast to the muscular dystrophies, cell death in SMA is not thought to be progressive, though nothing is yet known about the underlying defect (3).

\section{CHROMOSOMAL LOCALIZATION OF CHILDHOOD-ONSET PROXIMAL SMA}

All three forms of SMA have been mapped to chromosome 5q11.2-q13.3 (4-7). The localization of the mutation was refined by the identification of microsatellites that showed strong linkage disequilibrium with the disease (8-11). These studies indicated a high frequency of null alleles associated with the SMA phenotype, suggesting that deletions of the critical region are common in patients (12). Five independent YAC

Address correspondence and reprint requests to: Kay E. Davies, University of Oxford, Genetics Laboratory, Biochemistry Department, South Parks Road, Oxford OXI 3QU, United Kingdom. contigs have been constructed (12-17). However, these are inconsistent, due either to the inherent instability of this chromosomal region in YACs or to polymorphism resulting from variable copies of repetitive sequences, pseudogenes, and retrotransposon-like sequences within the region containing the mutation (18-21).

\section{CANDIDATE GENES FOR SMA}

\section{Survival Motor Neuron Gene}

To date, three candidate cDNAs have been reported. The Survival Motor Neuron gene (SMN) exists in two almost identical copies within a large inverted duplication of a $500-\mathrm{kb}$ region on $5 q 13$ (22). The gene encodes an ubiquitously expressed $1.7-\mathrm{kb}$ mRNA. The two copies of the gene differ by five single base pair changes. None of these would predict a change in protein sequence. Both genes are expressed, although the centromeric copy undergoes alternative splicing to produce a truncated transcript lacking exon 7 . Two of the single base pair changes lie in exons 7 and 8, enabling differentiation of the two copies by single-stranded conformation polymorphism analysis (SSCP) (Fig. 1). Deletion of exons 7 and 8 in the telomeric copy of SMN are detected in more than $95 \%$ of patients, whereas deletions of the centromeric exons 7 and 8 are consistent with a normal phenotype and found in 3-5\% of controls $(22,23)$. In approximately $5 \%$ of cases of SMA of all types, the telomeric version of exon 7 is absent by SSCP analysis while the telomeric exon 8 is present. Direct sequencing has shown that in these cases the telomeric exon 7 sequence is replaced by the centromeric copy. It has been suggested that this is due to gene conversion occurring between the two copies of the SMN gene. 


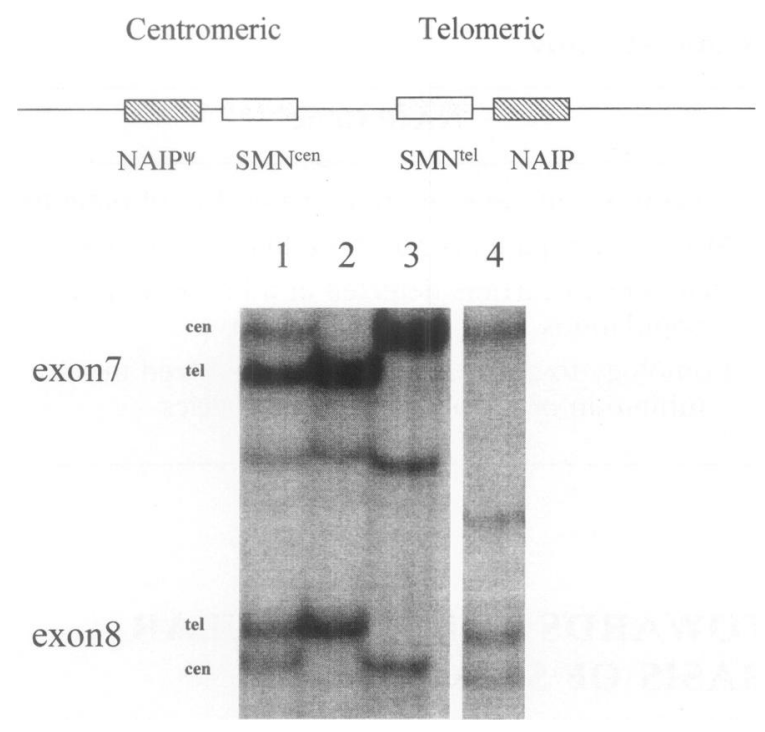

FIG. 1. Candidate genes for SMA lie in an inverted duplication spanning $500 \mathrm{~kb}$ on $5 q 13$

Single-stranded conformation polymorphism (SSCP) analysis allows resolution of the two copies of SMN exons 7 and 8 and the detection of deletions. Lane 1 , a healthy individual; Lane 2 , a healthy individual who lacks the centromeric version of SMN, deletion of which is not associated with a disease phenotype; Lane 3, a patient with type I SMA who is deleted for the telomeric version of SMN; Lane 4, a patient deleted for the telomeric version of exon 7 but who retains telomeric exon 8 (sequencing shows that this is due to a gene conversion event linking the centromeric version of exon 7 to the telomeric version of exon 8).

The confusing issue with SMN is that the same deletions of exons 7 and 8 of the telomeric gene are observed in all types of SMA. Very severely affected children, as well as adults with disease onset as late as the fourth decade, show identical deletions in exon 7 and 8 (24). In addition, asymptomatic siblings and parents of affected individuals have also been described with this deletion pattern (25-27). This suggests that, while deletion of exons 7 and 8 of SMN is a very good diagnostic marker for chromosome 5-linked SMA (28), it alone is not sufficient to define the disease phenotype. It may be that mutations in other genes on chromosome $5 \mathrm{q} 13$ are involved. Alternatively, the lack of genotype/ phenotype correlation for SMN deletions may be due to the presence of variable numbers of copies of the centromeric SMN gene which, if functional, could compensate for the lack of the telomeric copy. There is evidence from the study of microsatellites that the more severely affected patients possess fewer alleles at these loci than the more mildly affected patients. Consistent with these data, one report presented evidence for a relationship between gene dosage and the disease, although these studies remain to be confirmed (29).

Identification of a de novo deletion of SMN in two haploidentical siblings, one of whom was affected and previously thought to be nonchromosome 5 SMA, suggests that the rate of new mutations in SMA may be high (23). Indeed, in the initial studies of microsatellites, Melki and colleagues (12) demonstrated a case of de novo mutation. This may be a further reflection of the instability of this genomic region.

Strong evidence supporting an important role for SMN in the disease is provided by the finding of mutations in patients without deletions. Two patients in the original study had small deletions in the gene involving splice sites and one patient had a point mutation predicting an amino acid substitution (22). In a separate study, patients from consanguineous families were homozygous for a 4-bp deletion in SMN exon 3 leading to a frameshift (30). However, even in these families there was variable severity of the disease with the same mutation.

\section{Neuronal Apoptosis Inhibitory Protein Gene}

The neuronal apoptosis inhibitory protein (NAIP) gene maps close to SMN and is also duplicated in $5 q 13$ (31). Variable numbers of truncated copies of NAIP exist in the region. The presence of NAIP can be detected by PCR amplification of exon 5, which is only present in the full-length gene. Deletion of exon 5 is found in $45 \%$ of type I SMA patients and $18 \%$ of type II and III patients. Three out of 168 carriers were also found to harbor deletions of exon 5. The true incidence of deletions in the functional copy of NAIP in patients may be higher than observed but masked by the presence of truncated copies of the gene.

Evidence that NAIP may play a role in the pathogenesis of SMA comes from functional studies. The NAIP gene shows homology to two genes encoding baculovirus inhibitor of apoptosis proteins (31). Recent experiments in which NAIP is shown to suppress apoptosis in mammalian cells are supportive of the protein acting as a negative regulator of motor neuron apoptosis and, when deficient or absent, contributing to the SMA phenotype (32).

A third transcript XS2G3 mapping to the 
TABLE 1. Comparison of candidate genes for spinal muscular atrophy

\begin{tabular}{|c|c|}
\hline SMN Gene & NAIP Gene \\
\hline Disrupted or deleted in the majority of patients with SMA & Deletions only detected in a proportion of patients \\
\hline No correlation of mutation with disease severity & More severe patients are more likely to be deleted \\
\hline $\begin{array}{l}\text { Rare isolated cases of deletions in phenotypically normal } \\
\text { carriers }\end{array}$ & $\begin{array}{l}\text { Deletions in carriers detected at a low rate in all } \\
\text { populations }\end{array}$ \\
\hline No homology to known genes & $\begin{array}{l}\text { Homology to genes known to be involved in } \\
\text { inhibition of apoptosis in other species }\end{array}$ \\
\hline
\end{tabular}

candidate region has been shown to be deleted in patients but subsequently has been demonstrated to correspond to exon 7 of NAIP in the reverse orientation (33). It therefore detects the same deletions as NAIP.

\section{HOW MANY GENES ARE INVOLVED IN SMA?}

Deletion studies of SMA patients, carriers, and normals indicate that the size of the deletion in type I patients is larger, encompassing both SMN and NAIP, than that in type II and III patients (34-36). In fact types II and III appear to represent a continuum. One interpretation of these data is that both SMN and NAIP play a role in the disease process (Table 1).

The rare occurrence of either SMN or NAIP deletions in asymptomatic carriers suggests that other modifying genes may be involved. Although there is phenotypic variation in pedigrees, in general the severity of the disease breeds true, indicating that any modifier locus maps within chromosome 5q13. It is possible that neither of the two genes is the SMA gene and deletions in the true gene extend into these closely neighboring genes. An alternative explanation first proposed by Becker, suggests that there may be several different SMA alleles segregating in the population, which in combination determine disease severity. The model predicts both the rare occurrence of pseudodominance and the appearance of extreme differences in phenotype in a single family (37). Cases of pseudodominance have been observed, but the evidence for different alleles is still awaited.

\section{TOWARDS THE MOLECULAR BASIS OF SMA}

Although the pathology of SMA is considered to be primarily neuronal, the possibility of an intrinsic muscle defect has been indicated by in vitro experiments (38). Myoblasts from SMA patients which were innervated by neurite outgrowth from spinal cord slices showed a characteristic pattern of degeneration compared with control muscle. This observation suggests that muscle has an abnormal phenotype in the severe forms of SMA which may impair target dependent motor neuron survival in vivo.

Clues to the role of NAIP and SMN in the manifestation of SMA may come from the development of animal models. However, such models may be complicated by the presence or absence of multiple gene loci in other organisms. As yet it is unknown whether the genes are duplicated in the mouse. Whatever the arrangement, targeted disruption of even one of these genes in the mouse may be very informative. If mutations of both SMN and NAIP can explain the disease process, it will be fascinating to determine how these genes came to be duplicated in the course of evolution.

\section{ACKNOWLEDGMENTS}

We are grateful to the Muscular Dystrophy Group of Great Britain, the Medical Research Council, and the Muscular Dystrophy Association USA for financial support.

\section{REFERENCES}

1. Pearn JH. (1980) Classification of spinal muscular atrophies. Lancet i: 919-922.

2. Munsat TL, Davies KE. (1992) Workshop 
Report International SMA collaboration. Neuromuscul. Disord. 2: 423-428.

3. Dubowitz V. (1988) The clinical picture of spinal muscular atrophy. In: Merlini L, Granata C, Dubowitz V (eds). Current Concepts in Childhood Spinal Muscular Atrophy. Springer-Verlag, New York, pp. 13-19.

4. Brustowicz LM, Lehner T, Castilla LH, et al. (1990) Genetic mapping of chronic childhood onset spinal muscular atrophy to chromosome 5q11.2-13.3. Nature 344: 540-541.

5. Gilliam TC, Brustowicz LM, Castilla LH, et al. (1990) Genetic Homogeneity between acute and chronic forms of spinal muscular atrophy. Nature 345: 823-825.

6. Melki J, Abdelhak S, Sheth P, et al. (1990) Gene for chronic proximal spinal muscular atrophies maps to chromosome 5q. Nature 344: 767-768.

7. Melki J, Sheth P, Abdelhak S, et al. (1990) Mapping of acute (type I) spinal muscular atrophy to chromosome 5q12-q14. Lancet 336: 271-273.

8. McLean MD, Roy N, MacKenzie AW, et al. (1994) Two 5q13 simple tandem repeat loci are in linkage disequilibrium with type I spinal muscular atrophy. Hum. Mol. Genet. 3: 1951-1956.

9. Daniels RJ, Campbell L, Rodrigues NR, et al. (1995) Genomic rearrangements in childhood spinal muscular atrophy: Linkage disequilibrium with a null allele. J. Med. Genet. 32: 93-96.

10. DiDonato CJ, Morgan K, Carpten JD, et al. (1994) Association between AgC1-CA alleles and severity of autosomal recessive proximal spinal muscular atrophy. Am. J. Hum. Genet. 55: 1218-1229.

11. Burghes AHM, Ingraham SE, McLean M, et al. (1994) A multicopy dinucleotide repeat marker that maps close to the spinal muscular atrophy gene. Genomics 21: 394-402.

12. Melki J, Lefebvre S, Burglen L, et al. (1994) De novo and inherited deletions of the $5 q 13$ region in spinal muscular atrophies. Science 264: 1474-1477.

13. Kleyn PW, Wang CH, Lien LL, et al. (1993) Construction of a yeast artificial chromosome contig spanning the spinal muscular atrophy disease gene region. Proc. Natl. Acad. Sci. U.S.A. 90: 6801-6805.

14. Francis MJ, Morrison KE, Campbell L, et al. (1993) A contig of non-chimaeric YACs containing the spinal muscular atrophy gene in 5q13. Hum. Mol. Genet. 2: 1161-1167.
15. Carpten JD, DiDonato CJ, Ingraham SE, et al. (1994) A YAC contig of the region containing the spinal muscular atrophy gene (SMA): Identification of an unstable region. Genomics 24: 351-356.

16. Roy N, McLean MD, Besner-Johnston A, et al. (1995) Refined physical map of the spinal muscular atrophy gene (SMA) region at $5 \mathrm{ql} 3$ based on YAC and cosmid contiguous arrays. Genomics 26: 451-460.

17. van der Steege G, Draaijers TG, Grootscholten PM, et al. (1995) A provisional transcript map of the spinal muscular atrophy (SMA) critical region. Eur. J. Hum. Genet. 3: 87-95.

18. Theodosiou AM, Morrison KE, Nesbit AM, et al. (1994) Complex repetitive arrangements of gene sequence in the candidate region of the spinal muscular atrophy gene in 5q13. Am. J. Hum. Genet. 55: 1209-1217.

19. Sargent CA, Chalmers IJ, Leversha M, Affara NA. (1994) A rearrangement on chromosome 5 of an expressed human $\beta$-glucuronidase pseudogene. Mamm. Gen. 5: 791-796.

20. Selig S, Bruno S, Scharf JM, et al. (1995) Expressed cadherin pseudogenes are localized to the critical region of the spinal muscular atrophy gene. Proc. Natl. Acad. Sci. U.S.A. 92: 3702-3706.

21. Francis MJ, Nesbit MA, Theodosiou AM, et al. (1995) Mapping of retrotransposon sequences in the unstable region surrounding the spinal muscular atrophy locus in 5q13. Genomics 27: 366-369.

22. Lefebvre S, Burglen L, Reboullet S, et al. (1995) Identification and characterisation of a spinal muscular atrophy determining gene. Cell 80: 155-165.

23. Rodrigues NR, Owen N, Talbot $K$, et al. (1995) Deletions in the survival motor neuron gene on $5 \mathrm{ql} 3$ in autosomal recessive spinal muscular atrophy. Hum. Mol. Genet. 4: 631-634.

24. Brahe C, Servidei S, Zappata S, et al. (1995) Genetic homogeneity between childhood onset and adult onset autosomal recessive spinal muscular atrophy. Lancet 346: 741742.

25. Cobben JM, van der Steege G, Grootscholten $P$, et al. (1995) Deletions of the survival motor neuron gene in unaffected siblings of patients with spinal muscular atrophy. Am. J. Hum. Genet. 57: 805-808.

26. Hahnen E, Forkert R, Marke C, et al. (1995) Molecular analysis of candidate genes on chromosome 5q13: Evidence of homozygous 
deletions of the SMN gene in unaffected individuals. Hum. Mol. Genet. 4: 1927-1933.

27. Wang $\mathrm{CH}, \mathrm{Xu} \mathrm{J}$, Carter TA, et al. (1996) Characterization of survival motor neuron $\left(\mathrm{SMN}^{\mathrm{T}}\right)$ gene deletions in asymptomatic carriers of spinal muscular atrophy. Hum. Mol. Genet. 3: 359-365.

28. Rodrigues NR, Campbell L, Owen N, Rodeck $\mathrm{CH}$, Davies KE. (1995) Prenatal diagnosis of spinal muscular atrophy by gene deletion analysis. Lancet 345: 1049.

29. Velasco E, Valero C, Valero A, et al. (1996) Molecular analysis of the SMN and NAIP genes in Spanish spinal muscular atrophy (SMA) families and correlation between number of copies of ${ }^{\mathrm{C}} \mathrm{BCD} 541$ and SMA phenotype. Hum. Mol. Genet. 5: 257-263.

30. Bussaglia E, Clermont O, Tizzano E, et al. (1995) A frame-shift deletion in the survival motor neuron gene in Spanish spinal muscular atrophy patients. Nat. Genet. 11: 335337.

31. Roy N, Mahadevan MS, McLean M, et al. (1995) The gene for neuronal apoptosis inhibitory protein is partially deleted in individuals with spinal muscular atrophy. Cell 80: 167-178.

32. Liston P, Roy N, Tamai K, et al. (1996) Suppression of apoptosis in mammalian cells by
NAIP and a related family of IAP genes. $\mathrm{Na}$ ture 379: 349-353.

33. Thompson TG, DiDonato CJ, Simard LR, et al. (1995) A novel cDNA detects homozygous microdeletions in greater than $50 \%$ of type I spinal muscular atrophy patients. Nat. Genet. 9: 56-62.

34. Rodrigues NR, Owen N, Talbot $\mathrm{K}$, et al. (1996) Gene deletions in spinal muscular atrophy. J. Med. Genet. 33: 93-96.

35. Wirth B, Hahnen E, Morgan K, et al. (1995) Allelic association and deletions in autosomal recessive proximal spinal muscular atrophy: Association of marker genotype with disease severity and candidate cDNAs. Hum. Mol. Genet. 4: 1273-1284.

36. Burlet $\mathrm{P}$, Burglen $\mathrm{L}$, Clermont $\mathrm{O}$, et al. (1996) Large scale deletions of the 5q13 region are specific to Werdnig-Hoffmann disease. J. Med. Genet. 33: 281-283.

37. Emery AEH. (1991) Clinical and genetic heterogeneity in spinal muscular atrophy-The multiple allele model. Neuromuscul. Disord. 1: 307-308.

38. Braun $S$, Croizat $B$, Lagrange $M-C$, Warter J-M, Poindron P. (1995) Constitutive muscular abnormalities in culture in spinal muscular atrophy. Lancet 345: 694-695. 